\title{
Caravana da Matemática: uma experiência de divulgação científica em redes sociais
}

\author{
Beatriz Casulari da Motta Ribeird \\ DM-ICE-UFJF, Juiz de Fora, MG \\ Reginaldo Braz Batista|p \\ DM-ICE-UFJF, Juiz de Fora, MG \\ Sandro Rodrigues Mazorch $\beta$ \\ DM-ICE-UFJF, Juiz de Fora, MG \\ Nelson Dantas Louza Junion \\ DM-ICE-UFJF, Juiz de Fora, MG \\ Valéria Mattos da Rosa $\mathbb{F}^{\$}$ \\ DM-ICE-UFJF, Juiz de Fora, MG \\ Geovanna Vilela Avelan $\left.\right|^{\beta}$ \\ ICE-UFJF Juiz de Fora, MG \\ Letícia Naves de Souzd? \\ ICE-UFJF, Juiz de Fora, MG \\ Sara Cristina dos Santos $\$$ \\ ICE-UFJF, Juiz de Fora, MG
}

Resumo. A Caravana da Matemática é um projeto de extensão, realizado por professores e alunos de graduação do Departamento de Matemática da UFJF, que busca divulgar a matemática de forma divertida e atraente. Originalmente, as ações de divulgação eram feitas em formas de palestras, teatro, mágicas e outras atividades participativas em visitas a escolas de Juiz de Fora (MG) e região. Com a pandemia da Covid-19, as ações do projeto foram concentradas nas redes sociais. Nesse artigo, apresentamos nossa experiência de divulgação matemática nas redes sociais Instagram (@caravanadamatematica) e Facebook (facebook.com/caravanadamatematica).

Palavras-chave. Divulgação científica, Redes sociais, História da Matemática.

\section{Introdução}

A Matemática é uma ciência de destacada abrangência: é base de avanços científicos e tecnológicos, mas também é ferramenta essencial ao exercício da cidadania auxiliando indivíduos na leitura crítica de contextos sociais, econômicos e políticos. Portanto, preocupa verificar que o Brasil apresenta um quadro paradoxal: enquanto universidades e centros de pesquisa se destacam

\footnotetext{
${ }^{1}$ beatriz@ice.ufjf.br

2 reginaldobraz@ice.ufjf.br

3 sandro.mazorche@ufjf.edu.br

${ }^{4}$ nelsonlouza@ice.ufjf.br

${ }^{5}$ valeria.rosa@ufjf.br

${ }^{6}$ geovannaavelar@ice.ufjf.br

${ }^{7}$ leticianaves@ice.ufjf.br

${ }^{8}$ sara.santos@ice.ufjf.br
} 
internacionalmente na área, apenas cerca de 5\% dos egressos do ensino médio das escolas públicas dominam conteúdos básicos da disciplina segundo os dados apresentados em fevereiro de 2021 pelo Sistema de Avaliação do Ensino Básico (Saeb) [1]. As razões que podem tentar explicar essa disparidade são diversas e passam pela desigualdade na sociedade e a falta de recursos das escolas públicas, mas também por uma cultura de que a matemática é de fato difícil e inacessível.

Nesse contexto, surgiu a Caravana da Matemática. Esse é um projeto de extensão realizado por professores e alunos de graduação do Departamento de Matemática da Universidade Federal de Juiz de Fora (UFJF) com apoio das Pró-reitorias de Extensão e Graduação, que surgiu com a proposta de desconstruir os preconceitos com a matemática, propondo uma mudança da visão existente. O projeto propõe como ferramenta a divulgação científica. Mais do que isso, acreditamos na popularização da ciência no sentido apresentado por Germano e Kulesza [3]: a ampliação do conceito de divulgação científica, acrescida da problematização da comunicação ciência/público baseada nos interesses e nas necessidades sociais coletivas. Ainda, apostamos na divulgação científica, por concordar com Chaves [2] quando pontua que "nas atividades de divulgação, está-se liberto dos aspectos de currículo mínimo e, sobretudo, dos aspectos tantas vezes traumatizantes da avaliação, sendo possível contemplar apenas o interesse a despertar e a visão a enriquecer".

Ao propor atividades de divulgação científica, estamos, ainda, em consonância com o espírito do tempo [4 5]. Notamos que iniciativas como a da Caravana da Matemática vêm surgindo em diversas áreas e centros de pesquisa como tentativa de aproximar a ciência, o cientista e a universidade da comunidade externa, o que é fundamental especialmente em um momento em que a ciência vem passando por ataques e questionamentos. Como pontua Roque [4]: “...precisamos de mais diálogo, melhores estratégias de convencimento e iniciativas de divulgação científica abertas à autocrítica. Não basta defender a ciência a partir de posições de autoridade, calcadas na superioridade ou na neutralidade do saber científico". Mais do que nunca, faz-se necessária uma comunicação mais clara, direta e eficaz com o público fora da universidade e do meio científico em geral.

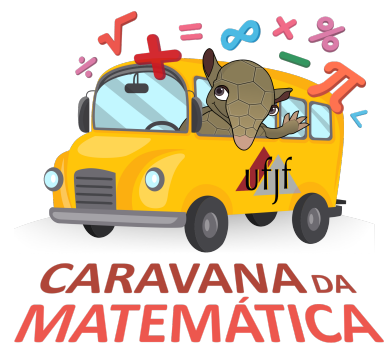

Figura 1: Logo da Caravana da Matemática.

A Caravana da Matemática funcionou em seu formato original de 2018 a 2020: fazendo divulgação matemática presencialmente em escolas de Juiz de Fora e região, em palestras no Centro de Ciências da UFJF, na Semana da Matemática do ICE/UFJF e em ações da Universidade, como o Domingo no Campus e o Ciência na Praça. Nesses dois anos, atendemos 66 escolas contemplando um público estimado em mais de 3.500 estudantes, fora os professores e outros profissionais da educação, além do público geral nos eventos abertos da UFJF. Em 2020, com a pandemia da Covid-19, houve a necessidade de nos reiventarmos. A transição para a atuação em modo virtual acabou por revelar novas potencialidades do projeto. Durante o período de atuação da Caravana da Matemática nas redes, vimos o projeto ganhar em abrangência, atingindo um público que antes não alcançávamos por limitações geográficas e orçamentárias. Este período levantou diversos desafios, mas permitiu que experimentássemos linguagens e ferramentas mais adequadas à divulgação científica em meio virtual. Além disso, nos inseriu em uma rede de perfis de divulgação matemática e científica em geral, em que pudemos contribuir. 


\section{A rede de perfis de divulgação matemática}

Atualmente, a internet é um importante espaço de discussão de assuntos os mais diversos possíveis. É o local em que hoje nascem formadores de opinião e não se pode negar a importância do que é levantado nas redes como norteador de ações de divulgação científica. Dessa forma, é natural haver perfis discutindo e apresentando ideias matemáticas no mundo virtual. Nesse cenário, especialmente no Instagram e no Facebook, encontramos perfis de divulgação matemática formada por pesquisadores, professores e alunos interessados em apresentar seus trabalhos em formatos diversos.

Notamos de imediato que essa rede é majoritariamente formada por:

1. Professores de educação básica que utilizam as plataformas como "cartão de visitas" para suas aulas particulares, materiais disponibilizados para outros professores ou canais de videoaulas no Youtube e plataformas pagas. Essa apresentação virtual, muitas vezes, é feita em forma de pequenas dicas sobre como decorar resultados ou algum "macete" matemático. Alguns desses perfis atingem poucas pessoas, outros têm dezenas de milhares de seguidores.

2. Alunos de graduação que apresentam seus interesses na área. As publicações costumam variar em curiosidades, dicas de livros e dicas de estudos. Observamos que esses são os perfis que mais utilizam as ferramentas de video do Instagram, como IGTV e Reels. Alguns desses alunos, mesmo ainda sem graduação completa, já estão inseridos no mercado de trabalho e aproveitam a visibilidade das redes como propaganda, como é o caso de perfis que trabalham com preparação para olimpíadas científicas.

3. Pesquisadores, professores universitários e alunos de graduação que estão envolvidos em projetos de divulgação que utilizam ainda Youtube ou blogs, como é o caso do Fantástico Mundo Matemático (@fantasticomundomatematico). Há ainda outros projetos que, como a Caravana da Matemática, migraram para a divulgação virtual na impossibilidade de atividades presenciais. Esse é o caso do Museu da Matemática da UFMG (@mumatufmg) e do MatEmFoco da UFSJ (@matemfoco).

4. Perfis institucionais que agem como divulgadores de matemática, como é o caso dos perfis do Instituto Nacional de Matemática Pura e Aplicada (IMPA), das Olimpíadas de Matemática das Escolas Públicas (OBMEP), da Sociedade Brasileira de Matemática (SBM), da Sociedade Brasileira de Matemática Aplicada e Computacional (SBMAC), Comitê de Mulheres da SBMAC, entre outros. Em geral, tais perfis divulgam artigos e eventos na área.

Nesse mar de perfis tão distintos, a Caravana da Matemática verificou que poderia também contribuir com a divulgação cientifica nas redes, mantendo o objetivo geral do projeto em atividade desde 2018. Nosso interesse é divulgar a matemática para o público em geral, apresentando publicações diárias que tem como motes: a matemática é uma importante ferramenta de resolução de problemas feita por seres humanos, está em constante construção e permite interlocução com diversas áreas. Sabemos que a divulgação científica depende do interesse e do background do público, mas acreditamos que se bem apresentada e fundamentada, tem o poder de cativar pessoas previamente interessadas em matemática ou não. Mais do que dar dicas ou repetir informações presentes em muitos lugares, gostaríamos de plantar a semente da pensamento matemático e contribuir para a mudança de cultura sobre essa disciplina.

\section{A experiência da Caravana da Matemática}

A Caravana da Matemática já tinha perfis tanto no Facebook quanto no Instagram. No entanto, o papel desses canais era de mera propaganda das atividades realizadas nas escolas. A partir de 
maio de 2020, os espaços passaram a ser mais explorados, com publicações diárias.

O processo de elaboração das publicações feitas em conjunto pelos alunos e professores é um processo de pesquisa: envolve o levantamento de temas que julgamos interessantes, a pesquisa bibliográfica e a relfexão sobre as informações levantadas, de modo que os textos e imagens além de atraentes, sejam corretos e claros. Isso faz com que o projeto tenha um caráter de formação de alunos pesquisadores bastante relevante.

A transição para o ambiente virtual não foi fácil. Aos poucos, testamos as ferramentas e as redes, tentando compreender o que funcionava ou não, até que chegamos a essencialmene três tipos de postagens: desafios, mini biografias e textos de divulgação.

Os desafios são publicações em que o público é convidado não somente a testar sua proficiência nas áreas básicas da Matemática, como também explorar a criatividade na resolução de um problema proposto toda semana com a solução dada na semana seguinte. Essas publicações têm bom engajamento e fornecem um mote para abordar temas e técnicas de Matemática assim como para reforçar o poder da linguagem da Matemática na resolução de problemas.
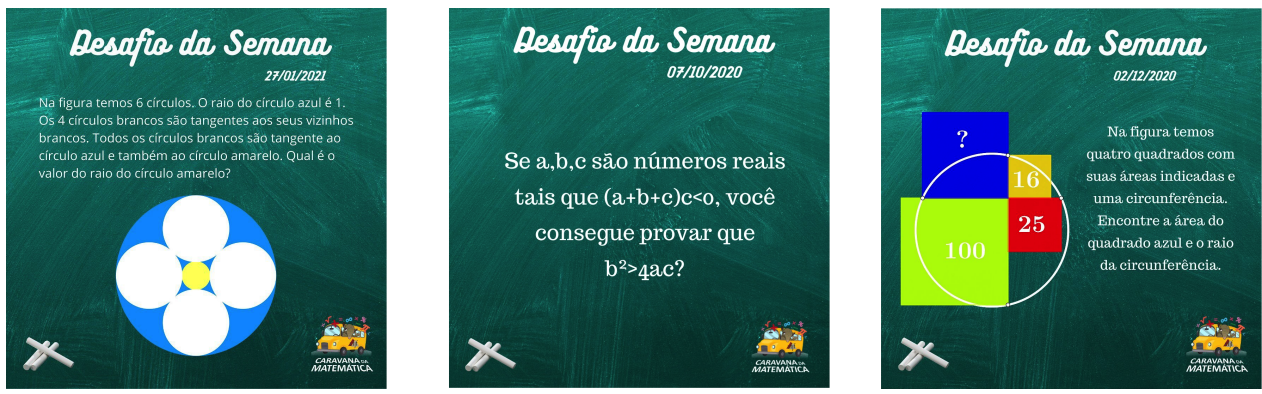

Figura 2: Exemplos de figuras de publicações de desafios.

As publicações de biografias de Matemáticos, mais do que homenagens a nomes que contribuíram para área, buscam humanizar e mostrar a diversidade de uma ciência construída por homens e mulheres das mais diversas partes do mundo. Em particular, as biografias de matemáticos brasileiros fazem muito sucesso. Por exemplo, a da professora emérita da UFRJ Maria Laura Mouzinho Leite Lopes (1917 - 2013) atingiu, no Facebook, um público estimado de 39.500 pessoas.
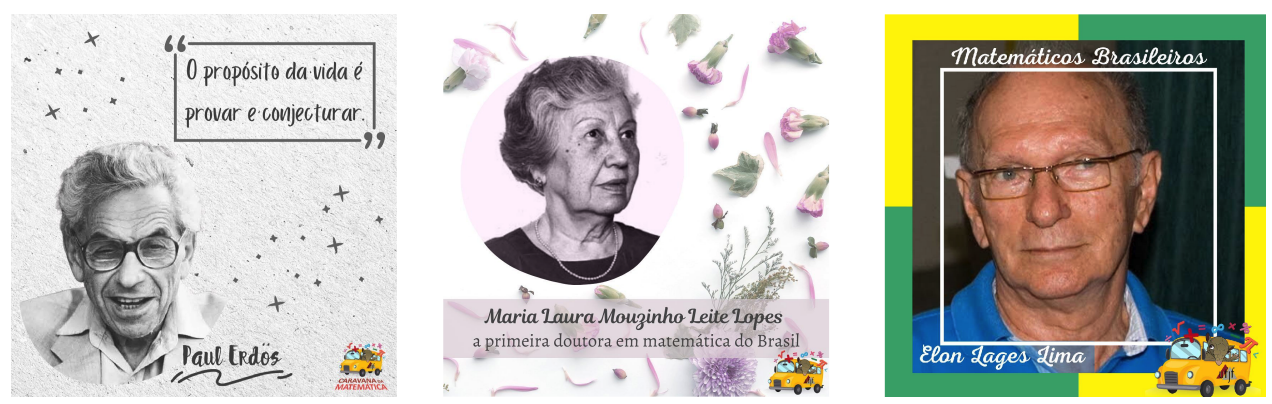

Figura 3: Exemplos de figuras de publicações de biografias.

As demais publicações abordam curiosidades matemáticas e problemas em aberto com enunciados simples acompanhados de históricos e possíveis implicações. A ideia é instigar o público e mostrar que conceitos já conhecidos podem ter relação com problemas práticos ou ainda não re- 
solvidos. Ainda, com problemas em aberto, buscamos mostrar que matemática está em constante construção, combatendo a ideia errada de que a Matemática é um corpo de conhecimento acabado.
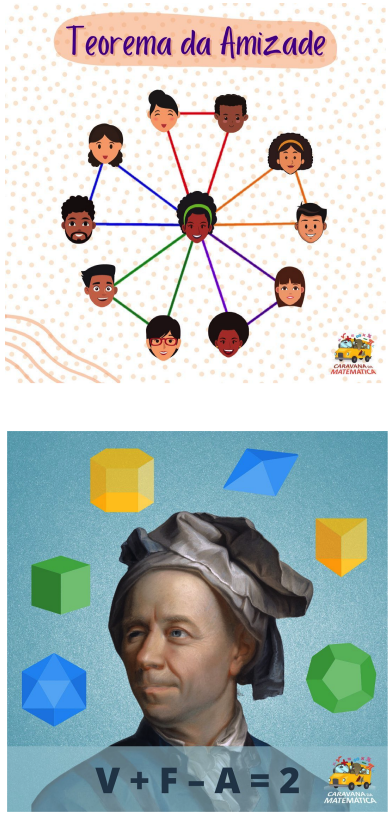

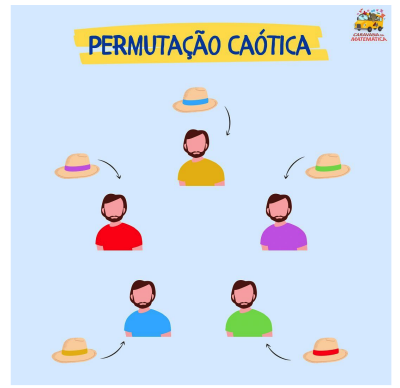

Um teorema sobre triângulos
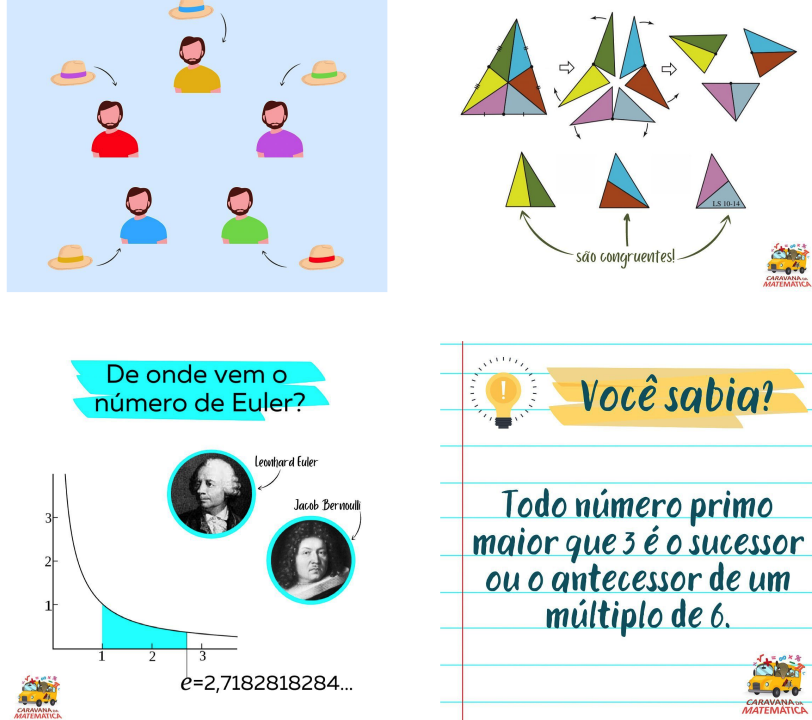

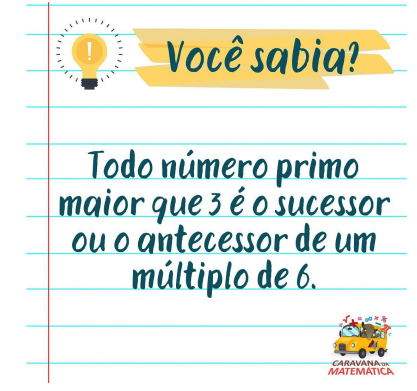

Figura 4: Exemplos de figuras de publicações de curiosidades.

O acompanhamento das publicações é feito pela equipe através dos sistemas de comentários, mas também pelas ferramentas das próprias plataformas, que medem engajamento e alcance (estimativa de quantas contas visualizaram o post pelo menos uma vez) das publicações. As estimativas indicam, por exemplo, que certas publicações no Facebook chegam a atingir dezenas de milhares de pessoas, enquanto outras atingem apenas uma centena. Isso levanta um questionamento: o que gera mais interesse?

Foi possível observar que publicações de biografias e problemas de apresentação simples ou familiares ao leitor têm um excelente engajamento. Há o fator memória afetiva: é atraente ler sobre um resultado que remete a lembranças escolares, especialmente para o público que não está mais em contato frequente com a matemática. Além disso, em conversas com estudantes, percebemos que também gera interesse ler sobre resultados, temas ou matemáticos dos quais eles já têm algum conhecimento. Sobre as publicações dos desafios, observamos que aqueles que a pessoa fez sem muito esforço ou com ferramentas simples são mais populares. Gostaríamos que outras publicações tivessem o mesmo êxito de engajamento que essas apresentadas. Assim, estamos buscando encontrar o melhor caminho para atrair o público para outro tipos de postagens.

$\mathrm{O}$ trabalho de divulgação em redes sociais apresenta alguns desafios. Um ponto a se observar diz respeito às limitações próprias das plataformas, como o máximo de 2200 caracteres por postagem no Instagram. Isso nos obriga a trabalhar mais as publicações para conseguir passar conceitos mais complexos em textos relativamente curtos. Curiosamente, o que nos parece pouco é muito para diversos seguidores: o engajamento em postagens com textos mais longos, em geral, é menor. Às limitações das ferramentas, se junta o próprio trabalho de traduzir conceitos formais em linguagem mais coloquial (própria de internet). É necessário ainda lutar para chamar a atenção do leitor em um ambiente cheio de interferências e carregado de informações das mais diversas possíveis como são as redes sociais. 
Mais do que atingir um público grande, é importante saber para quem estamos falando até mesmo para adequar o tipo de postagem. Se antes falávamos para adolescentes em escolas, agora isso mudou. Embora as ferramentas indiquem que nosso público é formado majoritariamente por professores e alunos de graduação em Matemática, acreditamos que levar mais informações para esse público tem um caráter formativo e extensionista no sentido da formação continuada. Os conhecimentos adquiridos com as publicações da Caravana da Matemática, e mesmo as próprias publicações, não só podem como já estão sendo utilizados em sala de aula (virtual, no momento) e materiais didáticos. Além disso, temos relatos de professores que indicam os perfis "de olhos fechados" para os alunos.

\section{Conclusões}

A Caravana da Matemática entrou nas redes por imposição da pandemia e foi necessário um grande esforço para compreender o espaço e criar conteúdo. Chegamos a alguns formatos que funcionam e que têm potencial, dentro do que nos propomos a fazer, mas ainda é uma questão identificar o que causa maior engamento. De qualquer modo, a experiência foi suficiente para compreendermos que é possível fazer extensão virtual, levando o conhecimento produzido na universidade para as redes e, dessa forma, contribuindo com a divulgação científica com informações de qualidade.

Em pouco menos de 1 ano de ações virtuais, alcançamos mais de 1200 seguidores no Instagram e 2200 no Facebook. Mas o alcance das publicações é maior, considerando o algoritmo de distribuição de publicações das redes, que as apresentam não só para seguidores, mas para pessoas com interesses comuns. Embora os números sejam modestos comparados com outros perfis, superam o público que atingíamos nas atividades presenciais. Dessa forma, esse é um alcance importante para o projeto, ainda mais se considerarmos o tipo de público. Um professor que utilize os conhecimentos adquiridos com a Caravana da Matemática com seus alunos faz com que essa informação chegue a dezenas ou centenas de alunos, que eram o público original do projeto de extensão.

Ainda, nossas atividades virtuais renderam muitos frutos para o projeto: o tornamos mais conhecido em outras partes do país; fizemos contato e ações de colaboração com outros perfis de divulgação científica e outros projetos de extensão; contribuímos para a formação de alunos de graduação da UFJF; contribuímos para a aproximação do público geral com a universidade.

Refletindo sobre tudo isso, concluímos que nossa experiência virtual foi extremamente proveitosa, trouxe novidades para o projeto e animou a equipe em um momento complicado. Certamente não abandonaremos esse braço de ação, mesmo quando do retorno presencial das atividades, já que ainda há espaço para explorar e crescer.

\section{Agradecimentos}

Agradecemos às Pró-Reitorias de Extensão e Graduação da Universidade Federal de Juiz de Fora pelo apoio logístico e pelas bolsas para alunos de graduação.

\section{Referências}

[1] $95 \%$ dos alunos saem do ensino médio sem conhecimento adequado em matemática. Revista Exame. 24 fev 2021. Disponível em: https://exame.com/brasil/ 95-dos-alunos-saem-do-ensino-medio-sem-conhecimento-adequado-em-matematica/. Acesso em: 28 abr 2021. 
[2] Chaves, M. A divulgação científica da Matemática. Anais do Segundo Debate sobre a Investigação Matemática em Portugal, Centro Internacional de Matemática, n 17, 2001. Disponível em: http://www.mat.uc.pt/ lnv/debate2/ManuelAralaChaves.html. Acesso em: 24 mar 2021.

[3] Germano, M. e KULESZA, W. Popularização da Ciência: uma revisão conceitual. Caderno Brasileiro de Ensino de Física v. 24, n. 1, 2007. DOI:https://doi.org/10.5007/\%25x

[4] Roque, T. O negacionismo no poder. Revista Piauí, n. 161, fev 2020. https://piaui.folha. uol.com.br/materia/o-negacionismo-no-poder/. Acesso em: 26 abr 2021.

[5] Silveira, E. Em reação a negacionismo, pesquisadores levam 'ciência descomplicada' às redes sociais. $B B C$ News. Disponível em https://www.bbc.com/portuguese/ salasocial-56421745. Acesso em: 24 mar 2021. 